1725c. Gruber. Grading

https://doi.org/10.30953/tmt.v2.59

\title{
Grading Obamacare on the Fundamentals of Care Delivery
}

Page 1 of 19

David Gruber and Peter Urbanowicz

Editor's note: Changes (some predict repeal) in the Affordable Care Act is an immanent prospect that will affect all stakeholders in healthcare, including patients, providers, and innovators in telemedicine. In this article and three others included in this issue of Telehealth and Medicine Today, David Gruber and Peter Urbanowicz inform our readers and, hopefully, help prepare them for changes that may be every bit as impactful in 2017 as were the initiating events that occurred seven years ago on March 23rd, 2010. The authors address issues of special relevance to stakeholders in telehealth in this article.

Grading Obamacare is based on five criteria: managing competition, increasing clinical effectiveness, improving efficacy, facilitating payment reform, and enhancing the experience of care. Here is an assessment of the impact of the Patient Protection and Affordable Care Act (PPACA) on these outcomes.

\section{Managing Competition: Grade: C}

Healthcare consolidation has increased significantly since passage of PPACA.

The number of hospital deals has increased from an average of 60 (involving 136 hospitals) in 2006 to 2010 to 97 (involving 227 hospitals) in 2011 to 2015.

Several studies have shown that hospital mergers result in higher prices for employers, consumers, and insurance companies. ${ }^{1}$ Hospitals are also acquiring physician practices, with nearly one-third of physicians in 2014 either working directly for a hospital or in practices that were at least partially owned by a hospital. ${ }^{2}$ Health insurance industry competition has also declined, with fewer companies offering commercial, Medicare Advantage and Medicaid Managed Care plans. 
1725c. Gruber. Grading

https://doi.org/10.30953/tmt.v2.59

Page 2 of 19

According to the National Association of Insurance Commissioners, there are 859 health insurers in the United States; the five largest-United, Anthem, Aetna, Humana and Cigna—generate revenues exceeding $\$ 350$ billion. ${ }^{3}$ Competition is exceedingly limited in four states-Alabama, Illinois, Arkansas and North Dakota —and limited in many others.

The Herfindahl-Hirschman Index $(\mathrm{HHI})$, a measure of market share distribution, has values ranging from zero (highly competitive) to 10,000 (non-competitive). According to the Federal Trade Commission (FTC), markets are classified into three categories: non-concentrated $(\mathrm{HHI}$ index $<1,500)$, moderately concentrated $\left(\mathrm{HHI}\right.$ of 1,500 to2,500) and concentrated $(\mathrm{HHI}>2,500) .{ }^{4}$

The median state $\mathrm{HHI}$ value for large group health insurance industry $\mathrm{HHI}$ has increased from 3,453 in 2011 to 4,256 in 2014 (for large insured groups). ${ }^{5}$ In 2000, the average state $\mathrm{HHI}$ approximated $2,000 .{ }^{6}$ According to the Commonwealth Fund, consolidation among private insurers "leads to premium increases, even though insurers with larger market shares generally obtain lower prices from healthcare providers." ${ }^{\prime}$ Limited competition has not precluded additional consolidation in the future, particularly among small-to-moderate size commercial and government plans in specific markets.

The pharmaceutical industry has also undergone significant consolidation. Increasing penetration of generic drug prescriptions from 54\% in 2003 to $88 \%$ in 2015 has masked an increase in the average price of a patented brand drug prescription from $\$ 110$ to $\$ 468$ per claim, reflecting a compound annual growth rate of $15.6 \%$ (Figure 1). ${ }^{8-10}$ The end of the generic "cliff" (i.e., major drug category expirations) has coincided with a shift in pharmaceutical strategy from developing products for population-based unmet needs, such as heartburn, anticholesterol, and hypertension drugs, to niche, specialty, and "orphan" markets with comparatively few patients where competition is somewhat limited and price increase unrestrained. 
1725c. Gruber. Grading

https://doi.org/10.30953/tmt.v2.59

Page 3 of 19

\section{AVERAGE COST PER DRUG CLAIM IN SELF-INSURED EMPLOYER PLAN*}

BRAND PRICES INCREASED > 13\% IN 2014

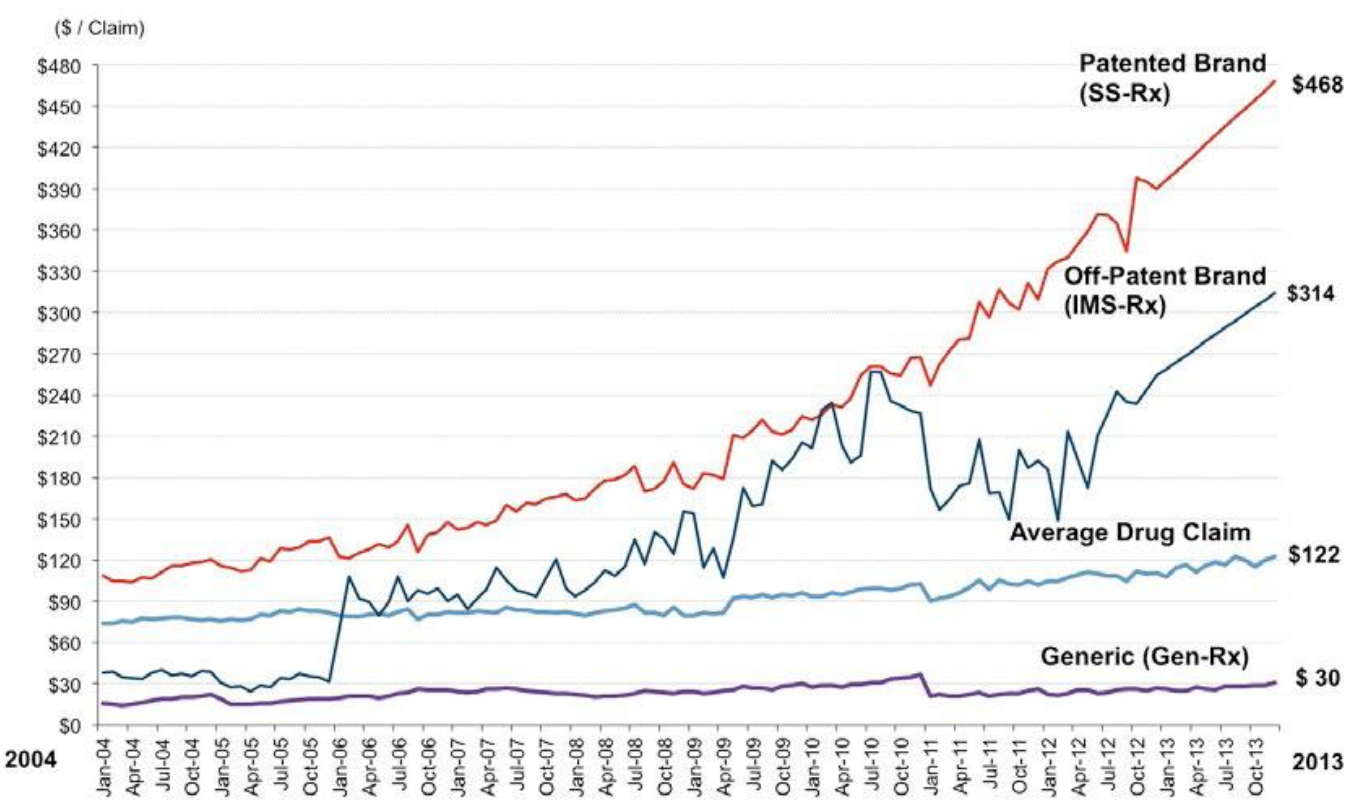

Source: Presentation by Stephen Schondelmeyer PharmD., PhD, Director of PRIME Institute, College of Pharmacy, University of Minnesota to Minnesota Health Action Group in April 2015

Figure 1. Comparative cost increases in patented and off-patent pharmaceuticals vs. generic cost.

Significant industry consolidation has occurred during the past 10 to 20 years and has more recently affected the generic drug industry. In 2014, a newly introduced medication for hepatitis $C$ reported sales of $\$ 10.3$ billion, with a full 12 -week course of therapy reaching $\$ 84,000$ per patient. U.S. prescription drug spending rose $13 \%$ in $2014 .{ }^{11}$ The average price of one type of insulin has increased from $\$ 600$ to $\$ 1,200$ per vial in less than three years. The cost for the generic antibiotic doxycycline has risen $8,281 \%$, asthma treatment albuterol by $4,014 \%$ and anti-cholesterol medication pravastatin by $573 \%{ }^{12,13}$

The Centers for Medicare \& Medicaid Service (CMS) does not include hospital and specialty drugs subject to medical claims (J-codes) in gross drug spending calculations. As a result, the vast majority of healthcare professionals are 
1725c. Gruber. Grading

https://doi.org/10.30953/tmt.v2.59

Page 4 of 19

unaware that actual prescription drug spending far exceeds CMS reported expenditures. Also, through 2023, CMS reports drug spending as a percent of National Health Expenditures is forecast to remain relatively constant at $9.4 \% .^{14}$ The reality is far different; drug spending is estimated to increase at a greater rate than any other sector within healthcare. Drug spending is also projected to surpass physician service expenditures by 2022 and to represent $20.1 \%$ of national health expenditures by 2023. ${ }^{15}$

\section{Increasing Clinical Effectiveness: Grade: C}

Despite the exceedingly high level of healthcare spending, the United States lags many countries in terms of health outcomes. More specifically, The Conference Board of Canada conducts multi-year research to measure relative health performance on 11 report card indicators among more than a dozen nations: life expectancy, self-reported health status, premature mortality, mortality due to cancer, mortality due to circulatory disease, mortality due to respiratory disease, mortality due to diabetes, mortality due to diseases of the musculoskeletal system, mortality due to mental disorders, infant mortality and mortality due to medical misadventures (Figure 2). The United States is one of only three nations to receive an overall $\mathrm{D}$ grade. ${ }^{16}$ 


\section{U.S. RANKING ON MORTALITY HEALTH INDICATORS}

\begin{tabular}{|c|c|c|c|c|c|c|c|c|c|c|c|}
\hline \multicolumn{12}{|c|}{ Health Indicators } \\
\hline & $\begin{array}{c}\text { Life } \\
\text { expectancy }\end{array}$ & $\begin{array}{l}\text { Self- } \\
\text { reported } \\
\text { heaith } \\
\text { status }\end{array}$ & $\begin{array}{l}\text { Premature } \\
\text { mortality }\end{array}$ & $\begin{array}{l}\text { Mortality } \\
\text { due to } \\
\text { cancer }\end{array}$ & $\begin{array}{l}\text { Mortality } \\
\text { due to } \\
\text { circulatory } \\
\text { diseases }\end{array}$ & $\begin{array}{c}\text { Mortality } \\
\text { due to } \\
\text { respiratory } \\
\text { diseases }\end{array}$ & $\begin{array}{l}\text { Mortality } \\
\text { due to } \\
\text { diabetes }\end{array}$ & $\begin{array}{c}\text { Mortality } \\
\text { due to } \\
\text { musculo- } \\
\text { skeletal } \\
\text { system } \\
\text { diseases }\end{array}$ & $\begin{array}{c}\text { Mortality } \\
\text { due to } \\
\text { mental } \\
\text { disorders }\end{array}$ & $\begin{array}{c}\text { Infant } \\
\text { mortality }\end{array}$ & $\begin{array}{l}\text { Mortality } \\
\text { due to } \\
\text { medical mis- } \\
\text { adventures }\end{array}$ \\
\hline Australia & (1) & Q & Q & $\theta$ & Q & (A) & B & (C) & (8) & B & (D) \\
\hline Austria & (C) & Q & (B) & (B) & (D) & (4) & (1) & (4) & (4) & (B) & (D) \\
\hline Belgium & C) & A & B & (B) & C & (D) & Q & (6) & (C) & (A) & n.a. \\
\hline Canada & (B) & (A) & (A) & (C) & (a) & (B) & C & (C) & (B) & C) & B \\
\hline Denmark & (D) & (4) & (B) & (D) & C & C & (B) & (D) & ( & (A) & A \\
\hline Finland & C) & (B) & (B) & (A) & D & a & (4) & B & C) & (4) & (4) \\
\hline France & (8) & B & (B) & (B) & (a) & a & Q & C) & (B) & (B) & C \\
\hline Germany & C & B & Q & B & (D) & a & (B) & Q & (B) & B & C) \\
\hline Ireland & C & a & (B) & C & (D) & (D) & B & (D) & (B) & Q & C \\
\hline Italy & a & B & A & B & B & A & C) & (B) & A & B & (A) \\
\hline Japan & A & D & (2) & (A) & (4) & C & Q & ( ) & A & A & Q \\
\hline Netherlands & (ㄱ) & a & ( & (D) & B & C & B & C & (D) & B & A \\
\hline Norway & (B) & a & ( ) & B & (8) & C & Q & (6) & C & ( ) & (4) \\
\hline Sweden & () & () & (4) & A & C) & (A) & (8) & (B) & (C) & A & C \\
\hline Switzerland & a & a & (1) & Q & (B) & a & (a) & C & C & (8) & n.a. \\
\hline U.K. & C) & a & (B) & C & C & (D) & Q & (D) & (C) & C & B \\
\hline U.S. & (D) & (1) & (D) & (B) & C & C & C) & C) & C & (D) & C \\
\hline
\end{tabular}

Figure 2. Relative health performance among countries surveyed by the Conference Board of Canada

U.S. life expectancy ranks only 26th of 36 OECD countries. ${ }^{17}$ Life expectancy actually declined slightly in 2015 to 78.8 years, driven primarily by obesity-related conditions such as heart and kidney disease, as well as substance abuse and suicide. Age-adjusted death rates increased for non-Hispanic black males and non-Hispanic white males and females. The infant mortality rate also increased, though not in a statistically significant manner. ${ }^{18}$ The U.S. health adjusted life expectancy (HALE) at birth, weighted by health status, of 69.1 years is only slightly ahead of Poland (68.7) and China (68.5) and lags the major European Union countries (range: 71.3 to 72.8 ) and Japan (74.9). ${ }^{19}$

The U.S. median for preventable death, measured as the years of potential life lost (YPL) before age 75 per 100,000 population, is 7,700 with a range of 5,700 for the healthiest states (Hawaii, Colorado) to 10,100 for the least healthy state (Mississippi). The YPL, unlike other mortality statistics, emphasizes the impact of 
1725c. Gruber. Grading

https://doi.org/10.30953/tmt.v2.59

Page 6 of 19

poor health on younger populations. 20 In comparison, most European nations and Japan have a YPL between 2,413 and 3,124, or 31 to $41 \%$ of the United States. ${ }^{21}$

A review of 61 U.S.-based studies published between 1990 and 2012 found an inconsistent association between cost and quality. Higher cost is not necessarily associated with higher quality. Clinical effectiveness is "what works"-symptom relief, quicker recovery, or longer life while minimizing adverse events. ${ }^{22}$

Evidence-based medicine has been defined as "the conscientious, explicit and judicious use of current best evidence in making decisions about the care of individual patients." ${ }^{23}$ Evidence-based healthcare broadens the concept to include an 'understanding of the patients', families', and doctors' beliefs, values and attitudes" into their decision-making. ${ }^{24} \mathrm{~A}$ significant gap exists between theory and practice, as it applies to clinical effectiveness:

- Healthcare delivery remains focused on acute intervention rather than primary, secondary, and tertiary prevention focused on preventing and minimizing the impact of diseases and conditions

- Despite the increasing focus on population health, and the availability of electronic medical record and claims analytics, significant gaps in care exist

- Care delivery and, in particular, transition management remain highly fragmented, though efforts to improve care navigation and coordination among acute, post-acute and community providers exist driven by the PPACA

- Widespread provider variation exists on measures of quality and outcomes as defined by CMS, the Agency for Healthcare Research and Quality (AHRQ), the National Quality Forum (NQF), the Joint Commission, the Leapfrog Group and others 
1725c. Gruber. Grading

https://doi.org/10.30953/tmt.v2.59

- Inadequate focus is being given to the social determinants of health Page 7 of 19 including socioeconomic, educational (literacy), psychosocial and environmental factors

- Patient and caregiver engagement, essential for self-management (treatment adherence, earlier intervention), remains limited

- Despite the wishes of many patients and their caregivers, end-of-life care, affecting 1.9 million Medicare beneficiaries, continues to be highly invasive for many and is estimated to account for $25 \%$ to $30 \%$ of total expenditures

- A shortage of primary care physicians, responsible for patient management across the continuum of services, is worsening due to their relatively low compensation, especially as compared to interventional specialists such as orthopedists, interventional cardiologists and radiation oncologists

Clinical effectiveness involves the "whole person" inclusive of behavioral healthmood disorders and anxiety affect $9.5 \%$ to $18.1 \%$ of the adult population in any given year. ${ }^{25}$ Behavioral health disorders have a significant impact on the total cost of care; i.e., those with co-morbid depression have average costs $53 \%$ higher (range: $34 \%$ to $141 \%$ depending on the specific condition) than those with a chronic condition or cancer alone due to psychosomatic and/ or treatment adherence issues. ${ }^{26}$ The under diagnosis and treatment of behavioral health conditions is common, estimated at $60 \%$ to $80 \% .{ }^{27} \mathrm{~A}$ recent report from Mental Health America, formerly known as the National Mental Health Association, states "only $41 \%$ of individuals with any mental illness report receiving treatment."28

\section{Improving Efficiency: Grade: D}

Despite our relatively young population, per capita health expenditures in the United States are far higher than those observed in other organizations for Economic Co-operation and Development (OECD) countries. ${ }^{29,30}$ Reduced per capita spending in Europe (and elsewhere) is driven by an increased focus on 
1725c. Gruber. Grading

https://doi.org/10.30953/tmt.v2.59

Page 8 of 19

primary care services, physician salaries $(33 \%$ to $50 \%$ of those in the United States) and regulatory and reimbursement constraints on new products and procedures. Furthermore, a single-payer system simplifies administration and serves as the backdrop for the lower per capita spending witnessed in these countries. ${ }^{31}$

In 2009, the Institute of Medicine (IOM) convened four meetings to identify opportunities to reduce healthcare costs by $10 \%$ within 10 years without negatively affecting outcomes. Workshops entitled Understanding the Targets, Strategies That Work, The Policy Agenda and Getting to 10\%: Opportunities and Requirements were attended by leading experts. ${ }^{32}$ Sources of waste totaling $\$ 765$ billion or $30.6 \%$ of total spending were identified (Figure 3): unnecessary services, inefficiencies, excessive administration, price variation, missed prevention opportunities, and fraud.

\section{ESTIMATES OF WASTE IN HEALTHCARE EXPENDITURES OF 10-30\%}

\begin{tabular}{|c|c|c|}
\hline Category & $\begin{array}{l}\text { Cost } \\
(\$ B)\end{array}$ & Sources of Waste \\
\hline Unnecessary services & $\$ 210$ & $\begin{array}{l}\text { - Overuse - beyond evidence established levels } \\
\text { - Discretionary use beyond benchmarks } \\
\text { - Unnecessary choice of higher-cost services }\end{array}$ \\
\hline $\begin{array}{l}\text { Inefficiently delivered } \\
\text { services }\end{array}$ & 130 & $\begin{array}{l}\text { - Mistakes-errors, preventable complications } \\
\text { - Uare fragmentation } \\
\text { - Unnecessary use of higher-cost providers } \\
\text { - Operational inefficiencies at care delivery sites }\end{array}$ \\
\hline $\begin{array}{l}\text { Excess administrative } \\
\text { costs }\end{array}$ & 190 & $\begin{array}{l}\text { - Insurance paperwork costs beyond benchmarks } \\
\text { - Insurers' administrative inefficiencies } \\
\text { - Inefficiencies due to care documentation requirements }\end{array}$ \\
\hline Prices that are too high & 105 & $\begin{array}{l}\text { - Service prices beyond competitive benchmarks } \\
\text { - Product prices beyond competitive benchmarks }\end{array}$ \\
\hline $\begin{array}{l}\text { Missed prevention } \\
\text { opportunities }\end{array}$ & 55 & Primary, secondary and tertiary prevention \\
\hline Fraud & 75 & - All sources-payers, clinicians and patients \\
\hline Total & $\$ 765$ & 2009 National Health Expenditures: $\$ 2,501 B$ \\
\hline
\end{tabular}


Further quantifying waste in the healthcare system, The Commonwealth Fund estimated $\$ 226$ billion for the over-utilization of healthcare services, leading to no patient benefit or even negative outcomes. ${ }^{33}$ In its seminal report entitled "Waste and Inefficiency in the U.S. Healthcare System," the New England Healthcare Institute identified cost savings of $\$ 100$ million to $\$ 10$ billion associated with inappropriate antibiotic usage for upper respiratory infections, the overuse of back-imaging studies, excessive surgery (hysterectomy, spinal, coronary) and percutaneous coronary interventions. ${ }^{34} \mathrm{~A}$ shift from fee-for-service to valuebased reimbursement would, at least partially, remediate over-utilization of healthcare services.

\section{Facilitating Payment Reform: Grade: B}

The most important fundamental healthcare delivery issue capable of incentivizing behavior change is reimbursement. The current healthcare system is still primarily based on fee-for-service payment system that rewards volume (at the highest possible prices) and not value. This has led to an excess of diagnostic procedures, advanced imaging scans and surgical interventions as well as significant variation in the site of service and procedure costs. Fee-forservice reimbursement has also led to care fragmentation, with poor transition management from hospitals to post-acute care facilities and home.

Obamacare, through the funding of pilot programs and CMS Innovation Center initiatives focused on value-based ("integrative") payment reform, has increased provider focus on quality, the care continuum, transition management, care navigation, post-acute care, the total cost of care, and elsewhere. It has also highlighted the importance of information technology (IT) system interoperability and the role of analytics to better manage the health of populations and individual patients. 
1725c. Gruber. Grading

https://doi.org/10.30953/tmt.v2.59

Page 10 of 19

Value is a function of quality and cost. Quality measurements have evolved to include structure, process, outcome, patient experience of care and access. Evidence-based practice requires a reduction in variability toward best practices. CMS has provided incentives to improve care processes and health outcomes, and reduce hospital readmissions and acquired conditions. Episode payment models (EPMs), especially the recently expanded Comprehensive Care Joint Replacement (CJR) and announced cardiovascular (bypass graft, stenting) initiatives, focus on the total cost of care for a 90-day episode across the continuum (hospital, post-acute and community-based care).

Accountable Care Organizations (ACOs) are intended to "lower healthcare costs, improve quality outcomes and improve the experience of care" by accepting financial responsibility, inclusive of risk management for the health of a targeted Medicare population. ${ }^{35}$ The initial CMS Pioneer ACO Model, launched in 2012 and designed for providers experienced with care coordination across multiple settings willing to accept bonuses and penalties based on CMS targets of patient spending, has been unsuccessful, with only nine of the original 32 participants still active. ${ }^{36}$ The more broadly utilized Medicare Shared Savings Plan initiative has had mixed results.

After several years of evolutionary changes, mostly voluntary but a few mandated, HHS Secretary Sylvia Burwell made the following announcement on January 26, 2015: "Today, for the first time, we are setting clear goals-and establishing a clear timeline-for moving from volume to value in Medicare payments. We will use benchmarks and metrics to measure our progress; and hold ourselves accountable for reaching our goals. Our first goal is for $30 \%$ of all Medicare provider payments to be in alternative payment models that are tied to how well providers care for their patients, instead of how much care they provide - and to do it by 2016 . Our goal would then be to get to $50 \%$ by 2018 . 
1725c. Gruber. Grading

https://doi.org/10.30953/tmt.v2.59

Page 11 of 19

Our second goal is for virtually all Medicare fee-for-service payments to be tied to quality and value; at least $85 \%$ in 2016 and $90 \%$ in 2018." 37 A full reversal of Ms.

Burwell's pronouncement would significantly slow the necessary transition from fee-for-service to value-based integrative care. Cost containment driven by an improvement in clinical effectiveness and care delivery efficiency cannot occur without a fundamental change in the reimbursement system.

\section{Enhancing the Experience of Care: Grade: D}

Obamacare has done little to alter the patient's overall experience of care. The Hospital Consumer Assessment of Healthcare Providers and Systems (HCAHPS) patient satisfaction survey is now required by CMS for all hospitals in the United States and measures "critical aspects of patients' hospital experiences: communication with nurses and doctors, the responsiveness of hospital staff, the cleanliness and quietness of the hospital environment, pain management, communication about medicines, discharge information, overall rating of hospital, and would they recommend the hospital." ${ }^{38}$

Since President Obama's inauguration in 2009, the percentage of patients who would rate their experience as a 9 or 10 increased from $64 \%$ to $72 \%$, and those who would definitely recommend their hospital from $68 \%$ to $71 \%$. A hospital satisfaction survey represents a snippet of a patient's overall healthcare experience.

In January 2015, CMS began reimbursing clinical staff for monthly 20-minute non-face-to-face interactions to improve care navigation (coordination) among Medicare beneficiaries with at least two chronic conditions; a comprehensive care plan, medication reconciliation $24 / 7$ access and electronic medical record are also required. Despite 35 million potentially eligible patients, enrollment was limited last year. 
1725c. Gruber. Grading

https://doi.org/10.30953/tmt.v2.59

Page 12 of 19

An article entitled "New Federal Policy Initiatives to Boost Health Literacy Can Help the Nation Move Beyond the Cycle of Costly 'Crisis Care,"' published in Health Affairs, describes a patient's experience as being "regularly confronted with complicated, confusing forms and instructions. As a result, too many people are hospitalized after being given ambiguous instructions about medications or failing to recognize the symptoms of a worsening condition. Effective practices have yet to be developed to assess whether patients properly use medications, complete tests, or receive referrals." 40

The authors reference the importance of literacy, plain language, provider communications and self-management to health outcomes. Nearly one-half of the adult U.S. population has difficulty understanding appointment slips, medical education brochures, physician directions, instructions on prescription drug bottles and consent forms. ${ }^{41}$ According to the Agency of Healthcare Quality and Research (AHRQ), self-management requires making lifestyle changes; monitoring signs, symptoms and biometric measurements indicative of a potential change in health status; and taking action when warranted (e.g., taking medications, calling a caregiver or physician).

In the current healthcare delivery system, primary care physicians have a limited amount of time to address the chronic care needs of patients, i.e., lifestyle issues, risk factors, co-morbidities and medications. The average face-to-face patient care time measured by direct observation was reported as 10.7 minutes, excluding visit specific work outside the examination room (2.6 minutes), figures far lower than the self-reported results of the National Ambulatory Medical Care Survey in 2003. ${ }^{41}$ Virtually no time is spent addressing nutrition, exercise, smoking cessation or mental health concerns. ${ }^{42,43}$

A more recent 2013 study suggests a downside of widespread electronic medical record (EMR) implementation is further erosion of "quality time" with patients. ${ }^{44}$ And, despite public health efforts, the number of Americans with at-risk behaviors 
1725c. Gruber. Grading

https://doi.org/10.30953/tmt.v2.59

Page 13 of 19

is staggering: a poor diet and/or sedentary lifestyle contributing to obesity (72.0 million); cigarette consumption (45.3 million); illicit drug use excluding marijuana (16.4 million); and "heavy" alcohol ingestion (15.0 million). ${ }^{45-47}$ Patient behaviors, particularly lifestyle choices, are the leading contributor to premature mortality, morbidity and disability. ${ }^{48}$

Behavioral patterns are difficult to change. According to the Prochaska and DiClemente Stages of Change Model, the practice of new behaviors requires a minimum of 3 to 6 months, whereas to avoid a relapse, a commitment to maintenance of 6 to 60 months is needed. 49 Many "programs" for weight loss, substance abuse and other behavior dependent conditions do not meet these time requirements; short-term interventions do not usually address the underlying root cause..$^{50,51}$

David Gruber, MD, MBA is a Managing Director and the Director of Research with the Alvarez \& Marsal Healthcare Industry Group in New York, specializing in strategy, commercial due diligence, analytics and new ventures. Dr. Gruber brings 33 years of diversified healthcare experience as a consultant, corporate executive, Wall Street analyst and physician.

Peter Urbanowicz, JD, is a Managing Director with the Alvarez \& Marsal Healthcare Industry Group in Washington, D.C., and leads the firm's healthcare compliance practice. He was formerly deputy general counsel of the United States Department of Health and Human Services and then general counsel of Tenet Healthcare Corporation (NYSE: THC). Mr. Urbanowicz has 25 years of experience in addressing challenging healthcare issues in government and private industry.

"Reprinted with permission, (C) 2016 Alvarez \& Marsal Holdings, LLC. All rights reserved. For more information, visit www.alvarezandmarsal.com." 
Articles in this series can be accessed here.

Obamacare: Coverage Without Cost Containment

"Trumpcare": What's Next

Grading Obamacare on the Fundamentals of Care Delivery

Winners and Losers in "Trumpcare"

\section{References}

1. Hospital mergers within state borders drive up costs; March 21, 2016. http://www. marketplace.org/2016/03/18/health-care/ hospital-mergerswithin-state-borders-drivecosts; and Robert Wood Johnson Foundation. How has hospital consolidation affected the price and quality of hospital care? February 2006. http://www.rwjf.org/en/library/research/ 2006/02/how-hashospital-consolidation- affected-the-price-and-quality-of.html.

2. Kane C. Updated data on physician practice arrangements: Inching toward hospital ownership. AMA Policy Research Perspectives; July 9, 2015. https://aharesourcecenter.wordpress. com/2015/07/09/ama-updatephysician-practice-arrangements-trend-data/

3. The Economist.

http://www.economist.com/sites/default/files/imagecache/original-size/ images/print-edition/20150627_WBC745.png

4. U.S. Department of Justice and Federal Trade Commission. Horizontal Merger Guidelines, August 2012.

5. http://kff.org/other/state-indicator/ large-group-insurance-marketcompetition/?activeTab=graph\&currentTimeframe $=0 \&$ startTimeframe $=3 \&$ sel ectedDistributions $=$ herfindahl-hirschman-index-hhi

6. Hilliard J, Ghosh C, Santerre R. Changing Health Insurance Market Concentration: Are Mergers Anticompetitive? University of Georgia Terry College of Business, 2008. https://www.chicagofed.org/ /media/others/events/2010/health-careconference/paper- hilliard-pdf.pdf 
1725c. Gruber. Grading

https://doi.org/10.30953/tmt.v2.59

7. Evaluating the impact of health insurance consolidation: Learning from

Page 15 of 19 experience.

http://www.commonwealthfund.org/publications/issuebriefs/2015/nov/evaluati ng-insurance-industry- consolidation

8. IMS Health National Prescription Audit, December 2012. http://www.pharmacytimes.com/publications/supplement/2013/genericsupple ment-2013/Generics-Outlook-Turning-to-Innovation-After-the-Patent-Cliff

9. IMS Institute for Health Informatics. Global Medicines in 2020: Outlook and Implications. http://connect.dcat.org/blogs/patricia-van-arnum/ 2016/02/02/what-is-ahead-for-the-generic- drug-market\#.WEszcLIrKM8

10. Presentation by Stephen Schondemeyer PharmD, PhD, Director of Prime Institute, College of Pharmacy, University of Minnesota to the Minnesota Health Action Group, April 2015.

11. IMS report; April 14, 2015. http://www.reuters.com/article/2015/04/14/ushealth-spending-medicinedUSKBN- 0N508I20150414

12. http://news.yahoo.com/soaring-genericdrug- prices-draw-senate-scrutiny141933064--finance.html

13. http://www.hangthebankers.com/genericdrug- prices-soar-up-to-8000/

14. National Health Expenditures Table11. http:// www.cms.gov/ResearchStatistics-Data- and-Systems/Statistics-Trends-and-

Reports/NationalHealthExpendData/National- HealthAccountsProjected.html

15. Calculated by A\&M based on CMS National Health Expenditure forecasts for pharmaceutical and total spending, and estimates of specialty drug revenues by Stephen Schondemeyer PharmD, PhD, Director of Prime Institute, College of Pharmacy, University of Minnesota.

16. How Canada Performs. The Conference Board of Canada International Ranking: Health; February 2012 data. http://www.conferenceboard.ca/hcp/details/health.aspx

17. The Huffington Post. U.S. Life Expectancy Ranks 26th In the World, OECD Report Shows; 11/21/2013. http://www.huffingtonpost. com/2013/11/21/uslife-expectancy-oecd_n_4317367.html 
1725c. Gruber. Grading

https://doi.org/10.30953/tmt.v2.59

Page 16 of 19

18. Centers for Disease Control. Mortality in the United States, 2015. NCHS Data Brief, No. 267, December 2016.

http://www.cdc.gov/nchs/data/hus/hus15.pdf\#019

19. WHO Health Life Expectancy at Birth: 2000-2015.

http://gamapserver.who.int/gho/ interactive_charts/mbd/hale_1/atlas.html

20. Robert Wood Johnson Foundation. County Health Rankings and Roadmaps:

Building a Culture of Health, County by County.

http://www.countyhealthrankings.org/

21. http://stats.oecd.org/index.aspx?queryid= 30124\#

22. PubMed Health. About Clinical Effectiveness Research.

https://www.ncbi.nlm.nih.gov/pubmedhealth/aboutcer/

23. David Sackett, William Rosenberg, Muir Gray, Brian Haynes \& Scott

Richardson. Evidence based medicine: what it is and what it isn't [internet].

BMJ; 13 January 1996. http://www. bmj.com/content/312/7023/71

24. Masic I, et al. Evidence Based Medicine - New Approaches and Challenges.

Acta Inform Med. 2008; 16(4): 219-225.

https://www.ncbi.nlm.nih.gov/pmc/articles/PMC3789163/.

25. National Institute of Mental Health. The Numbers Count: Mental Disorders in America. National Institute of Mental Health, May 2012.

http://wwwapps.nimh.nih.gov/health/ publications/the-numbers-count-mentaldisorders-in-america.shtml\#Intro.

26. Milliman Research Report. Chronic conditions and co-morbid psychological disorders, July 2008. http://us.milliman.com/insight/ research/health/pdfs/chronic-conditions- and-comorbid-psychologicaldisorders/

27. Kessler RC, et al. The Epidemiology of Major Depressive Disorder Results from the National Comorbidity Survey Replication (NCS-R). JAMA, 289(23): 3095-3105. http://jamanetwork. com/journals/jama/fullarticle/196765

28. Parity or Disparity: The State of Mental Health in America, 2015. http://www.mentalhealthamerica.net/sites/default/files/Parity\%20or\%20Dispa rity\%202015\%20Report.pdf 
1725c. Gruber. Grading

https://doi.org/10.30953/tmt.v2.59

Page 17 of 19

29. Healthcare Spending in the United States and Selected OECD Countries. http://facts.kff. org/chart.aspx?ch=1952

30. NationMaster.com.

http://www.nationmaster.com/graph/peo_age_str_65_yea_and_oveagestructure-65-years-over

31. Saltman R. Cost control in Europe: Inefficiency is unethical. The Hastings Center Healthcare Cost Monitor, November 2009.

http://www.thehastingscenter.org/uploadedFiles/ Publications/Primers/2009Health-Care- Cost-Monitor-Act-1.pdf

32. The Healthcare Imperative: Lowering Costs and Improving Outcomes Workshop Series Summary (2010); The National Academies Press, 2011. https://www.ncbi.nlm.nih.gov/pubmed/21595114

33. The Commonwealth Fund. Overuse and Systems of Care: A Systematic Review; May 24, 2013. http://www.commonwealthfund.org/ publications/inbrief/2013/may/overuse-andsystems-of-care

34. New England Healthcare Institute. Waste and Inefficiency in the U.S. Healthcare System, 2008. Waste Landscape.

http://www.nehi.net/writable/publication_files/file/waste_clinical_care_report_ final.pdf

35. Muhlestein D., Continued Growth of Public and Private ACOs. Health Affairs Blog; February 19, 2013. http://healthaffairs.org/ blog/2013/02/19/continuedgrowth-of-public- and-private-accountable-care-organizations/

36. https://innovation.cms.gov/initiatives/Pioneer-aco-model/

37. HHS Press Office. Better, Smarter, Healthier: In historic announcement, HHS sets clear goals and timeline for shifting Medicare reimbursements from volume to value; January 26, 2015.

http://www.hhs.gov/about/news/2015/01/26/better-smarter-healthier-inhistoric-announcement-hhs-sets-cleargoals- and-timeline-for-shiftingmedicare-reimbursements-from-volume-to-value.html 
1725c. Gruber. Grading

https://doi.org/10.30953/tmt.v2.59

38. HCAHPS: Patients' Perspectives of Care Survey.

Page 18 of 19

https://www.cms.gov/Medicare/ Quality-Initiatives-Patient-Assessmentinstruments/ HospitalQualitylnits/Hospital- HCAHPS.html.

39. http://content.healthaffairs.org/content/early/2012/01/18/hlthaff.2011.1169.full

40. National Network of Libraries of Medicine New England Region. Health literacy. http://nnlm.gov/outreach/consumer/hlthlit.html

41. Gottschalk A, Flocke SA. Time spent in face-to-face patient care and work outside the examination room. Ann Fam Med. 2005;3(6):488-93.

https://www.ncbi.nlm.nih.gov/pmc/articles/PMC1466945/

42. Yawn B, Goodwin MA, Zyzanski SJ, Stange KC. Time use during acute and chronic illness visits to a family physician. Fam Pract. 2003;20(4):474-7. http://www.pubpdf.com/ pub/12876124/Time-use-during-acute-andchronicillness-visits-to-a-family-physician

43. Tai-Seale M, McGuire T. Time allocation in primary care with competing demands. Presented at the Economics of Population Health: Inaugural Conference of the American Society of Health Economists, TBA, Madison, WI, June 4, 2006. http://ashecon.

org/conference/2006/abstracts/payments/time_allocation_in_primary_care_w ith_competing_demands/

44. Healthcare IT News. Is your EHR damaging the patient-provider relationship? Physician concern points to a larger worry that EHRs can sometimes negatively. http://www.healthcareitnews. com/blog/your-ehr-damagingpatient- provider-relationship

45. http://www.cdc.gov/obesity/data/adult.html

46. Centers for Disease Control and Prevention. 2011. Vital Signs: Current Cigarette Smoking Among Adults Aged $\geq 18$ Years-United States, 20052010. Morbidity and Mortality Weekly Report; 60(35):1207-12; https://www.cdc.gov/MMWR/preview/mmwrhtml/ mm6035a5.htm

47. SAMHSA. Nationwide Survey Shows Most Illicit Drug Users and Heavy Alcohol Users Are in the Workplace and May Pose Special Problems; 2007. 
1725c. Gruber. Grading

https://doi.org/10.30953/tmt.v2.59

Page 19 of 19

http://workforcesolutionstexoma.com/Nationwide_Survey_Shows_Most_Illicit _Drug_Users.pdf

48. Schroeder. We Can Do Better. NEJM 2007;357:1221-1228, Figure 1 adapted from McGinnis, et al. The Case for More Active Health Policy Attention to Health Promotion. Health Affairs 2002; 21:78-93.

http://www.nejm.org/doi/full/10.1056/NEJMsa073350\# t=article 64.

49 UCLA Center for Human Nutrition. Prochaska and DiClemente's Stages of Change Model.

http://www.cellinteractive.com/ucla/physcian ed/stages change.html

50. Evaluating the Impact of Health Insurance Consolidation: Learning From

Experience. http://www.commonwealthfund.org/publications/ issuebriefs/2015/nov/evaluating-insurance- industry-consolidation

51. Sheppard Mullin. Exploring the Relationship Between Price and Competition Among Physician Practices; October 29, 2014.

http:/www.sheppardhealthlaw.com/2014/10/articles/ antitrust/exploring-therelationship-between- price-and-competition-among-physician- practices/

\section{Category: Commentary}

Tags

Affordable Care Act, Affordable Care Act, AHRQ, claims analytics, clinical effectiveness, electronic medical record, experience of care, Gruber, hospital mergers, Joint Commission, managing competition, NQF, Obamacare, payment reform, pharmaceutical industry, primary care physicians, Urbanow 